\title{
LA-UR-19-22794
}

Approved for public release; distribution is unlimited.

Title: $\quad$ Space and Endo-Atmospheric NuDet Surveillance Experimentation and Risk-Reduction (SENSER) Official Photographs

Author(s): $\quad$ Sutton, Kevin Matthew

Valdez, Sandra M.

Budden, Brent Scott

Intended for: $\quad$ For future conference slides and publications, demos to potential customers and public.

Issued: 2019-03-28 
Disclaimer:

Los Alamos National Laboratory, an affirmative action/equal opportunity employer, is operated by Triad National Security, LLC for the National Nuclear Security Administration of U.S. Department of Energy under contract 89233218CNA000001. By approving this article, the publisher recognizes that the U.S. Government retains nonexclusive, royalty-free license to publish or reproduce the published form of this contribution, or to allow others to do so, for U.S. Government purposes. Los Alamos National Laboratory requests that the publisher identify this article as work performed under the auspices of the U.S. Department of Energy. Los Alamos National Laboratory strongly supports academic freedom and a researcher's right to publish; as an institution, however, the Laboratory does not endorse the viewpoint of a publication or guarantee its technical correctness. 


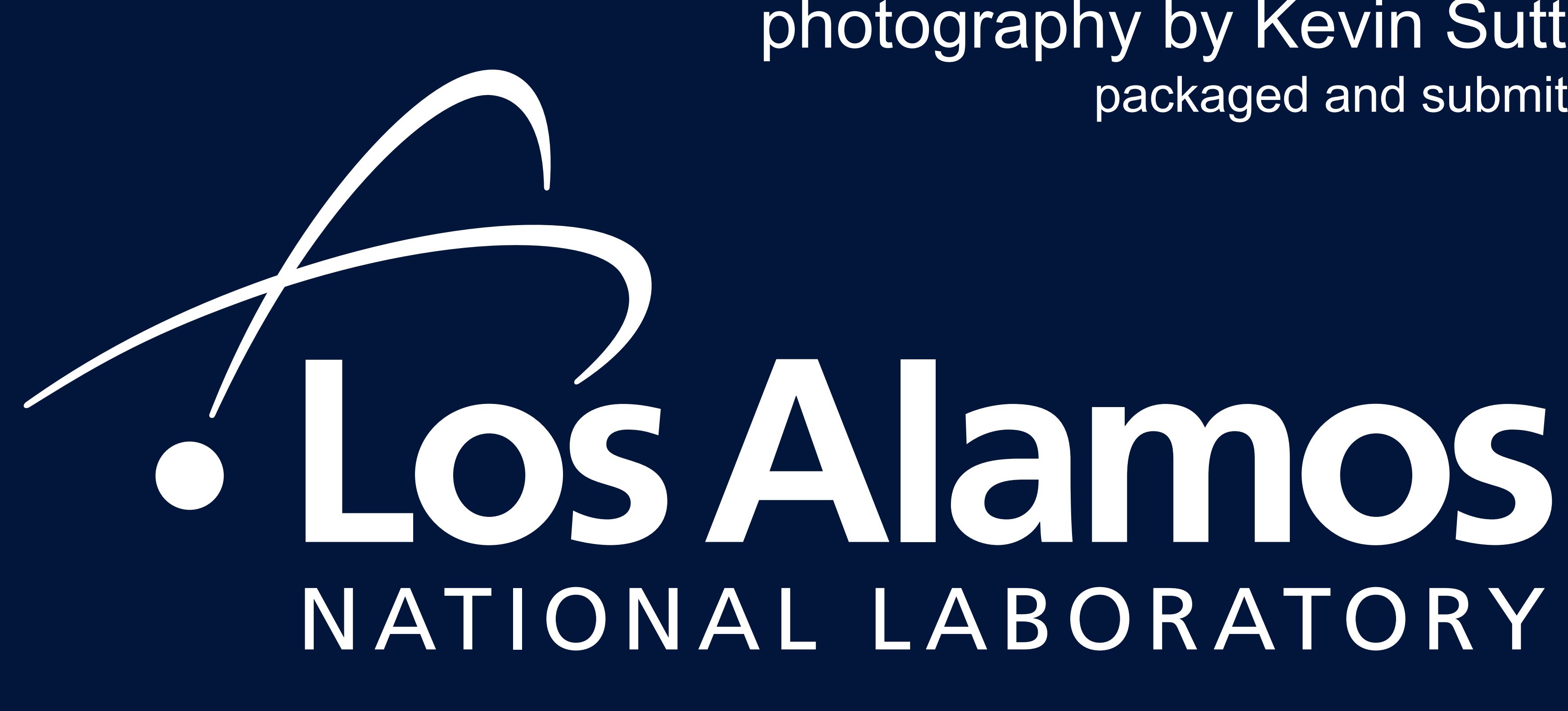

EST. 1943

\section{Space and Endo-Atmospheric NuDet Surveillance Experimentation and Risk-Reduction (SENSER)}

Official Photographs - February 2019 


\section{SENSER - Experiment Suite}




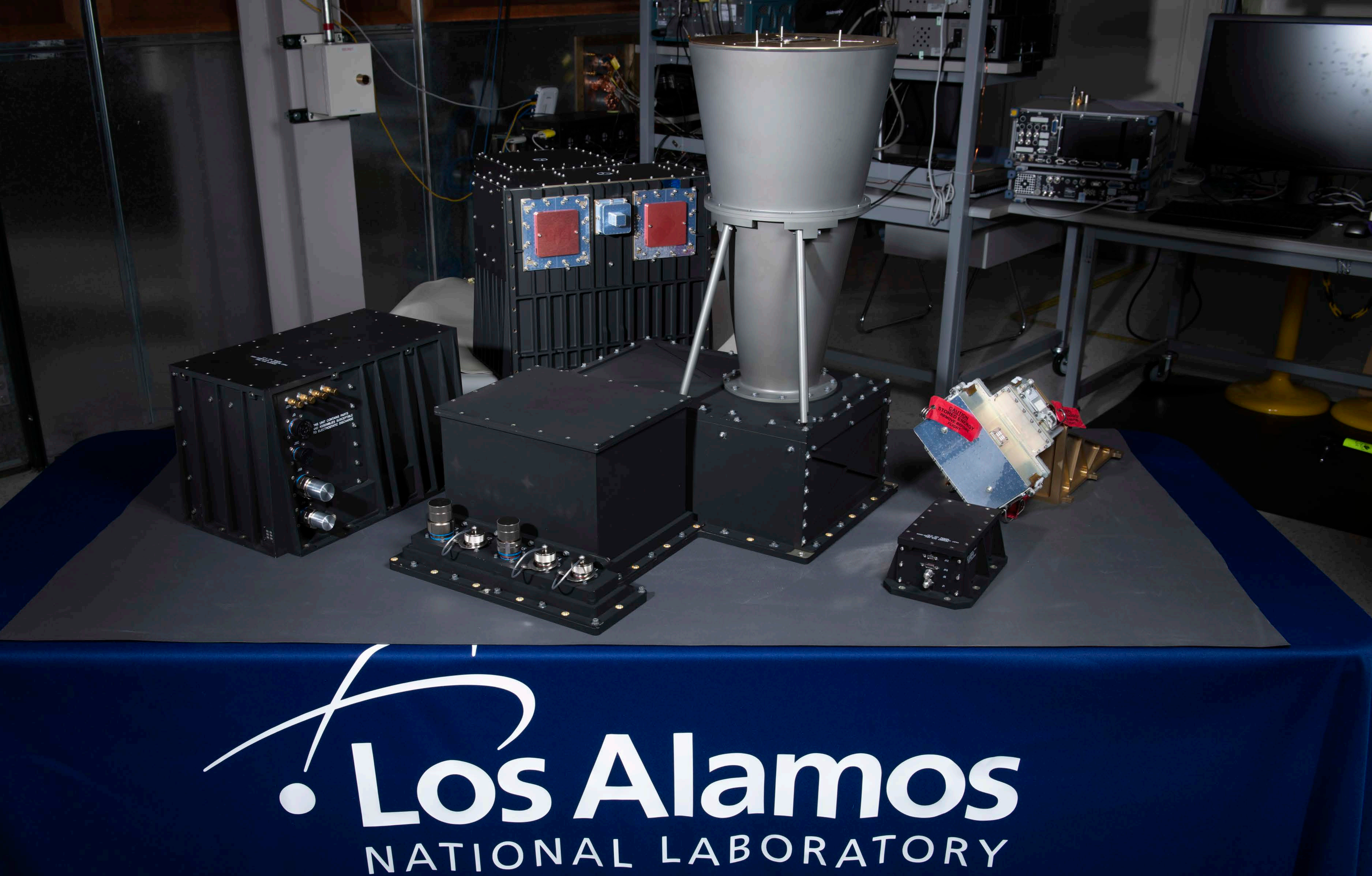

EST. 1943 


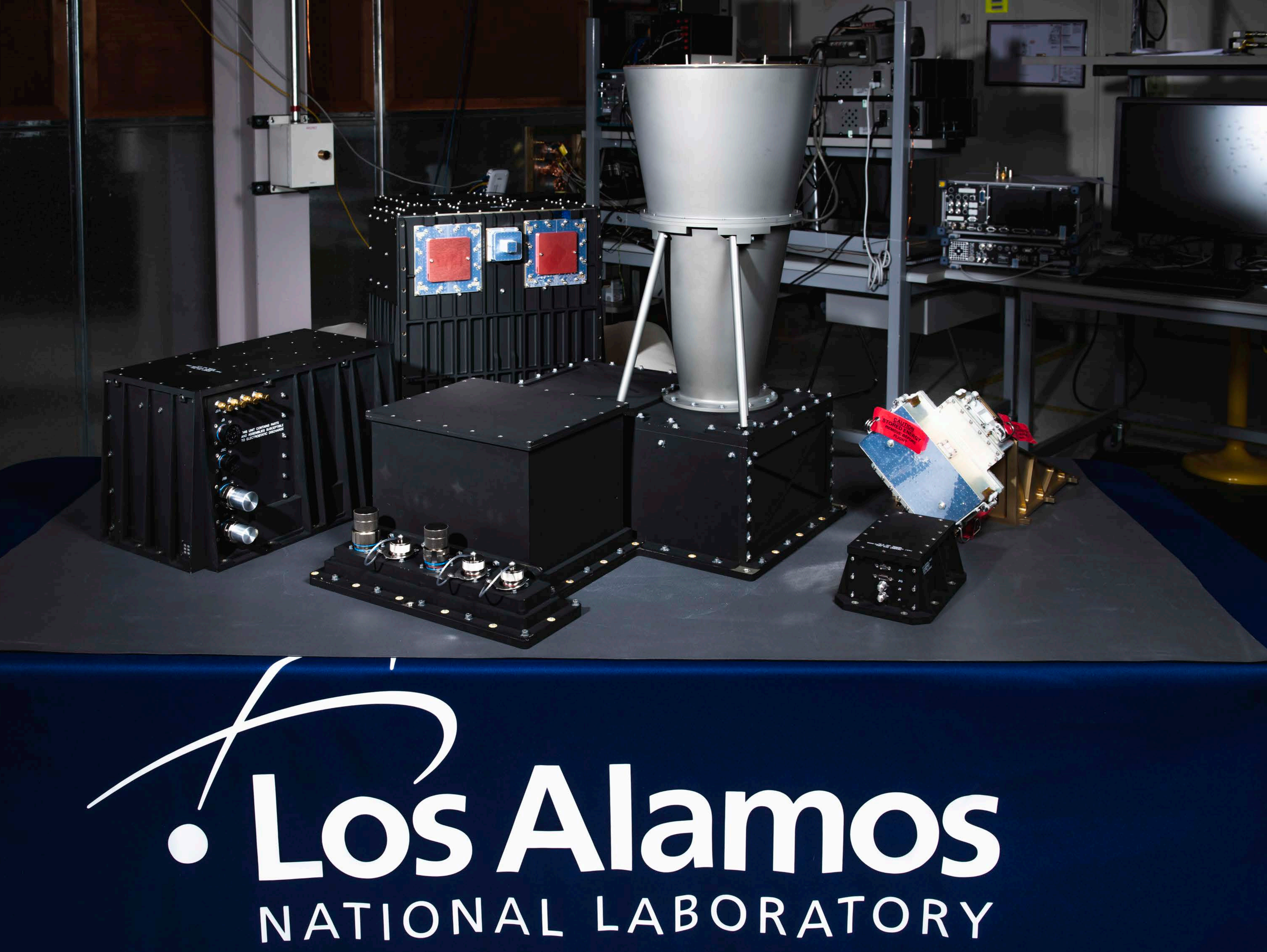

EST. 1943 


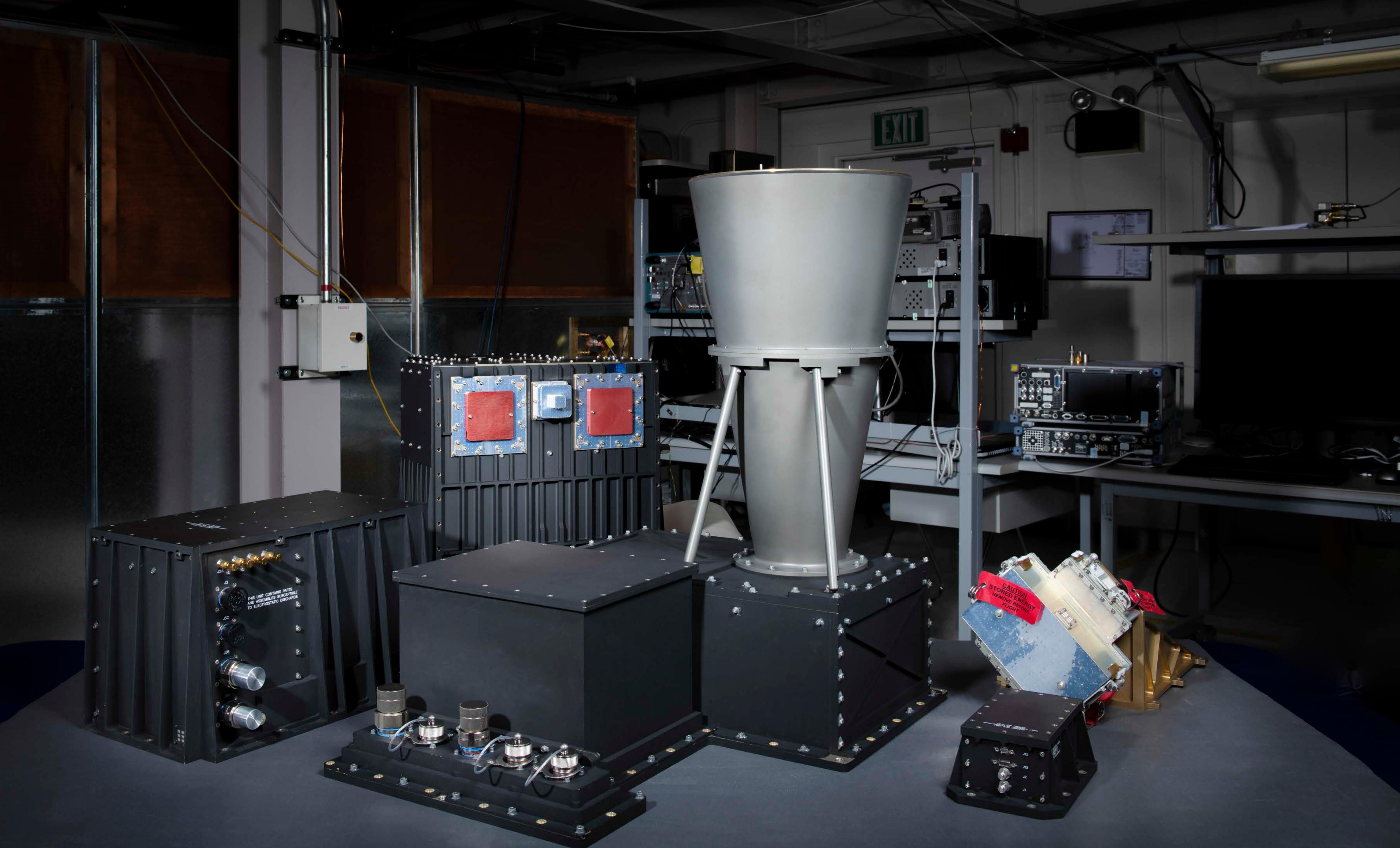


SENSER - HRE 


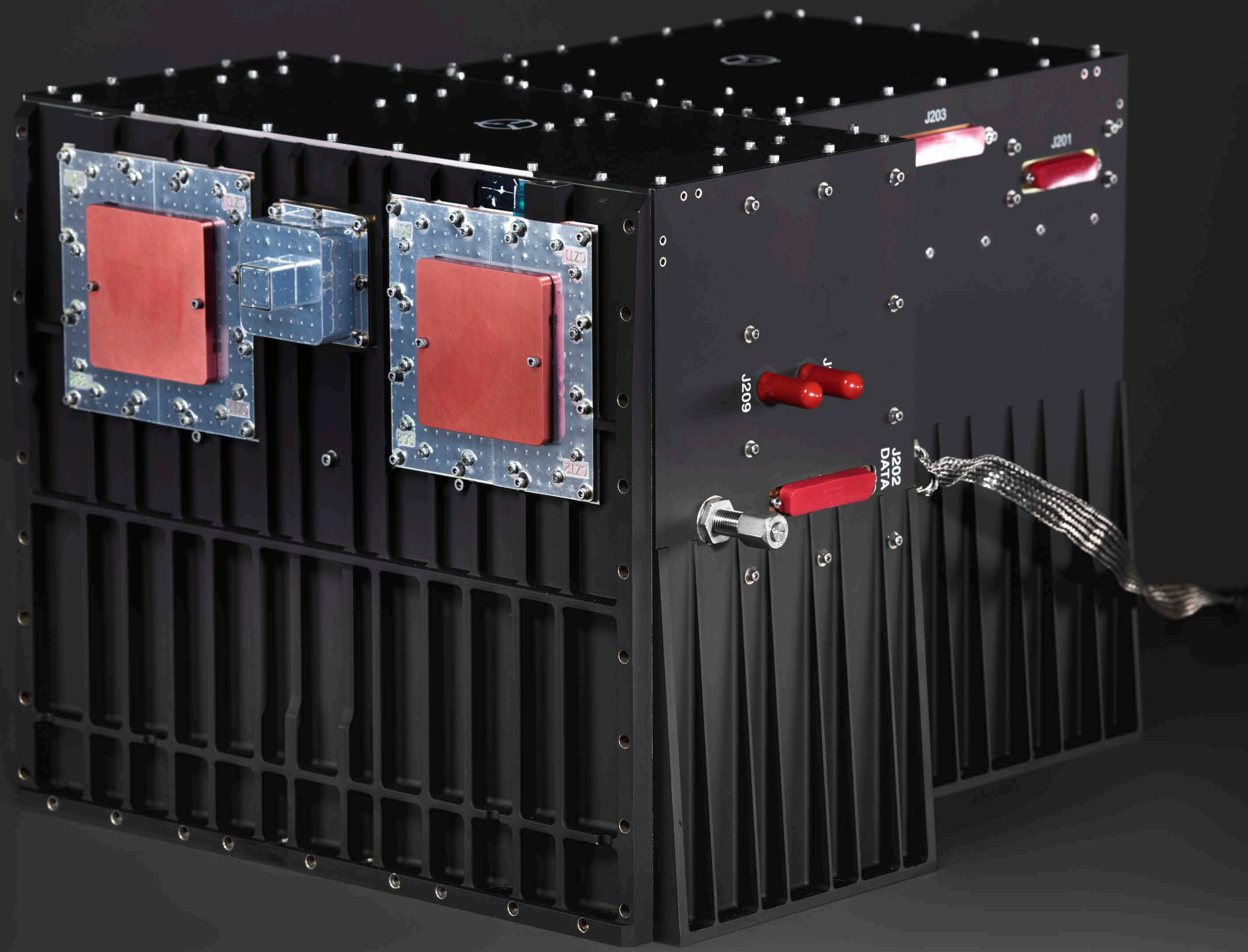




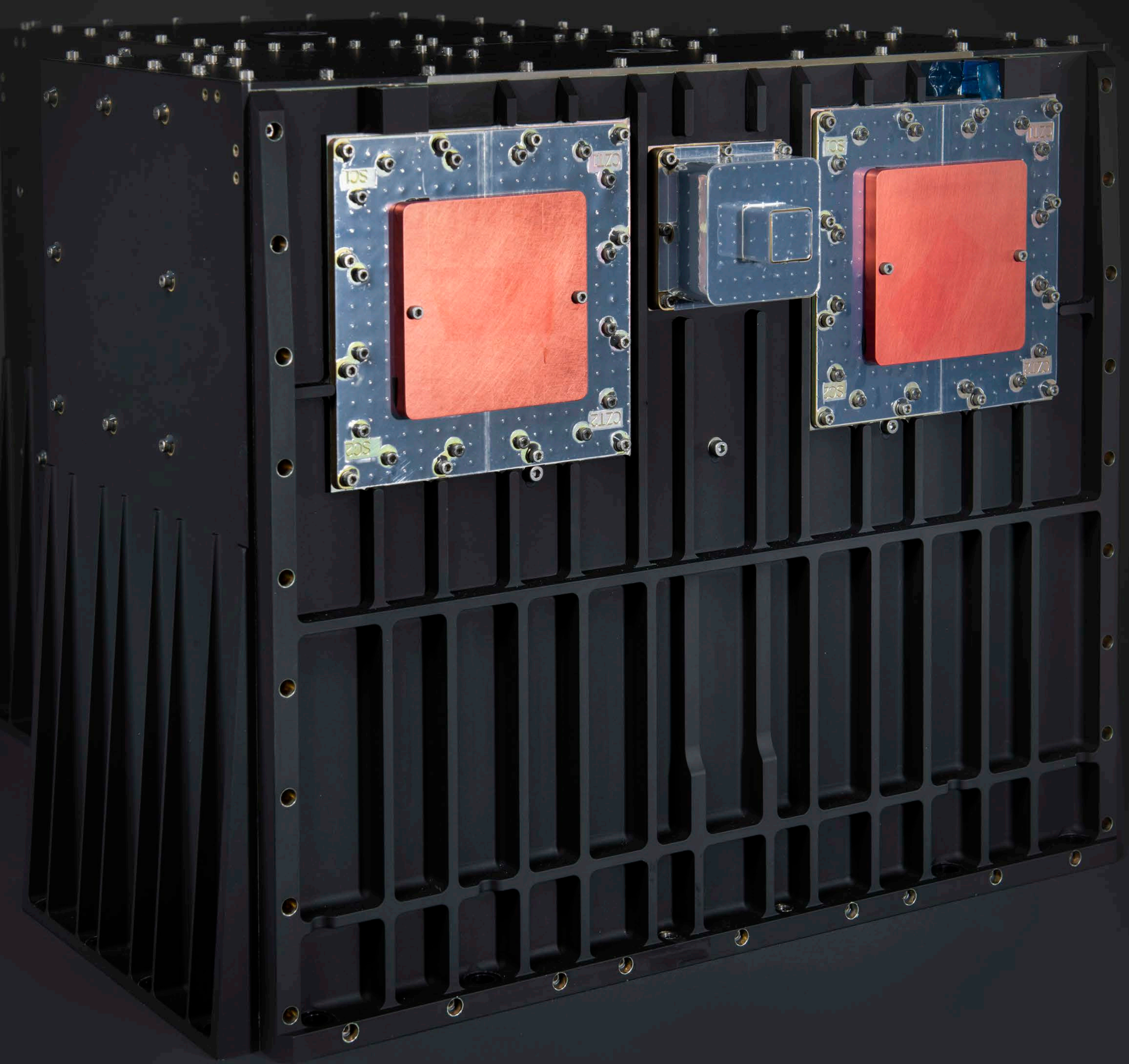




\section{SENSER - RFS \\ SENSER}

Los Alamos National Laboratory

\section{政}




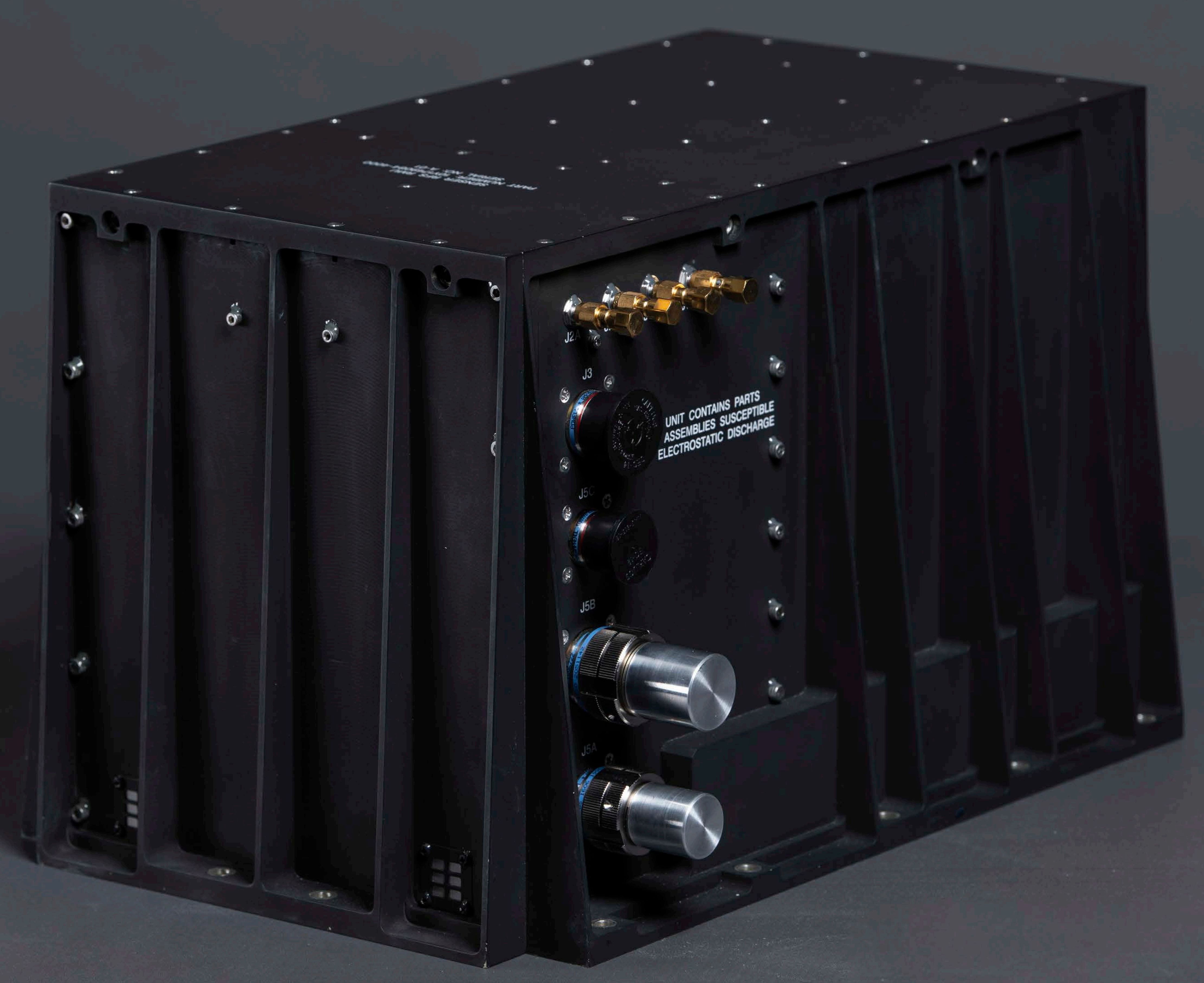




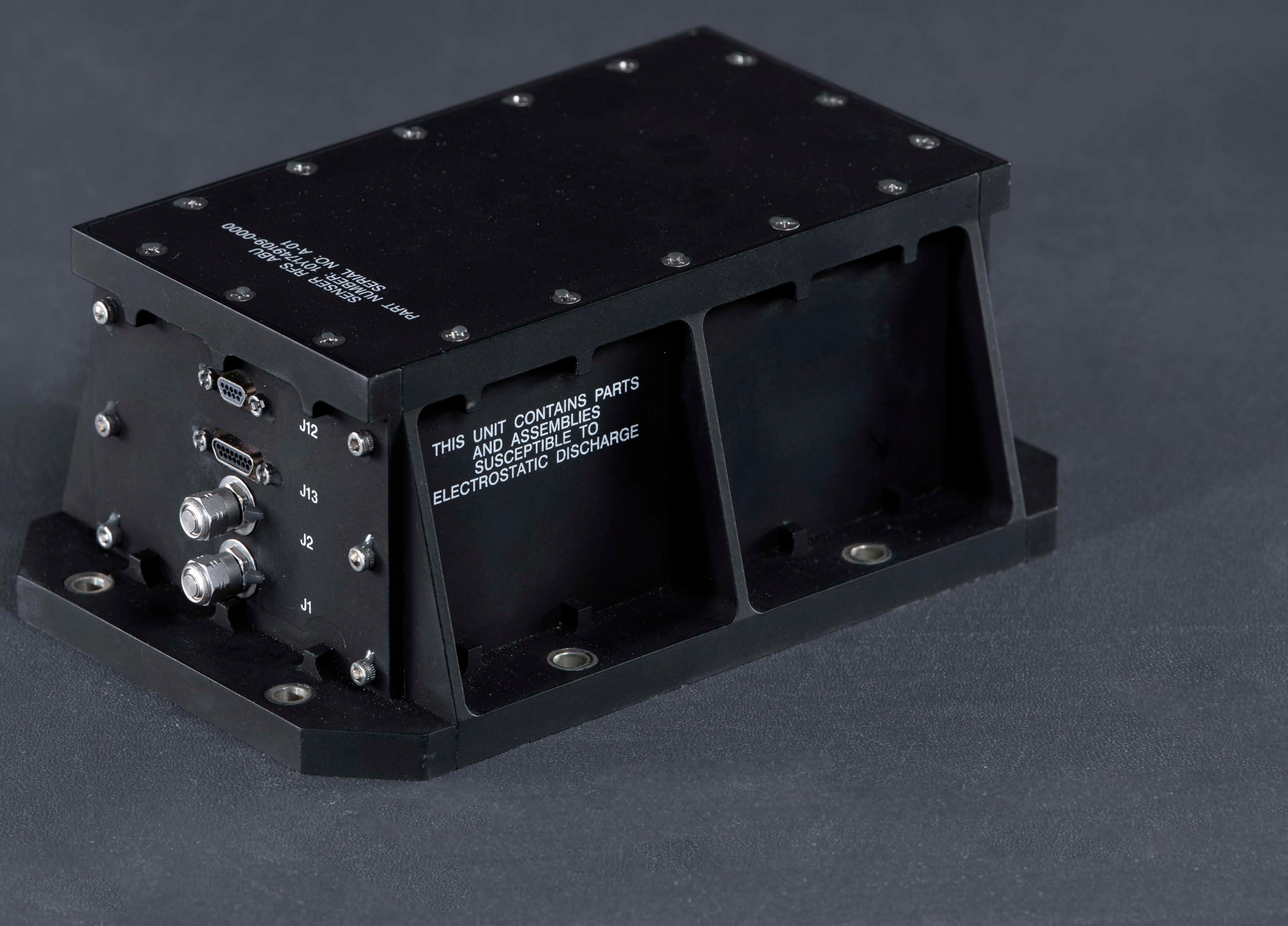




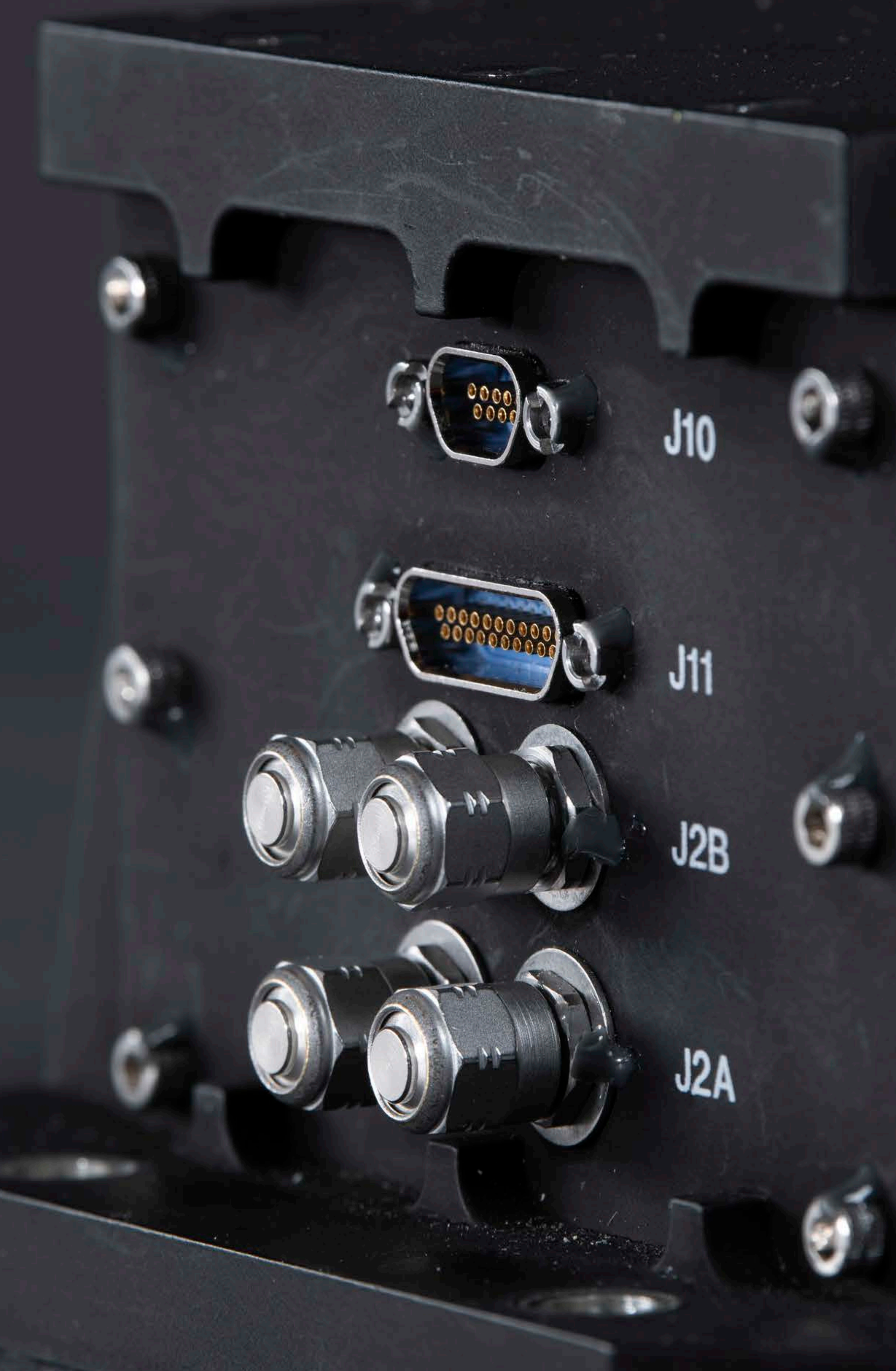




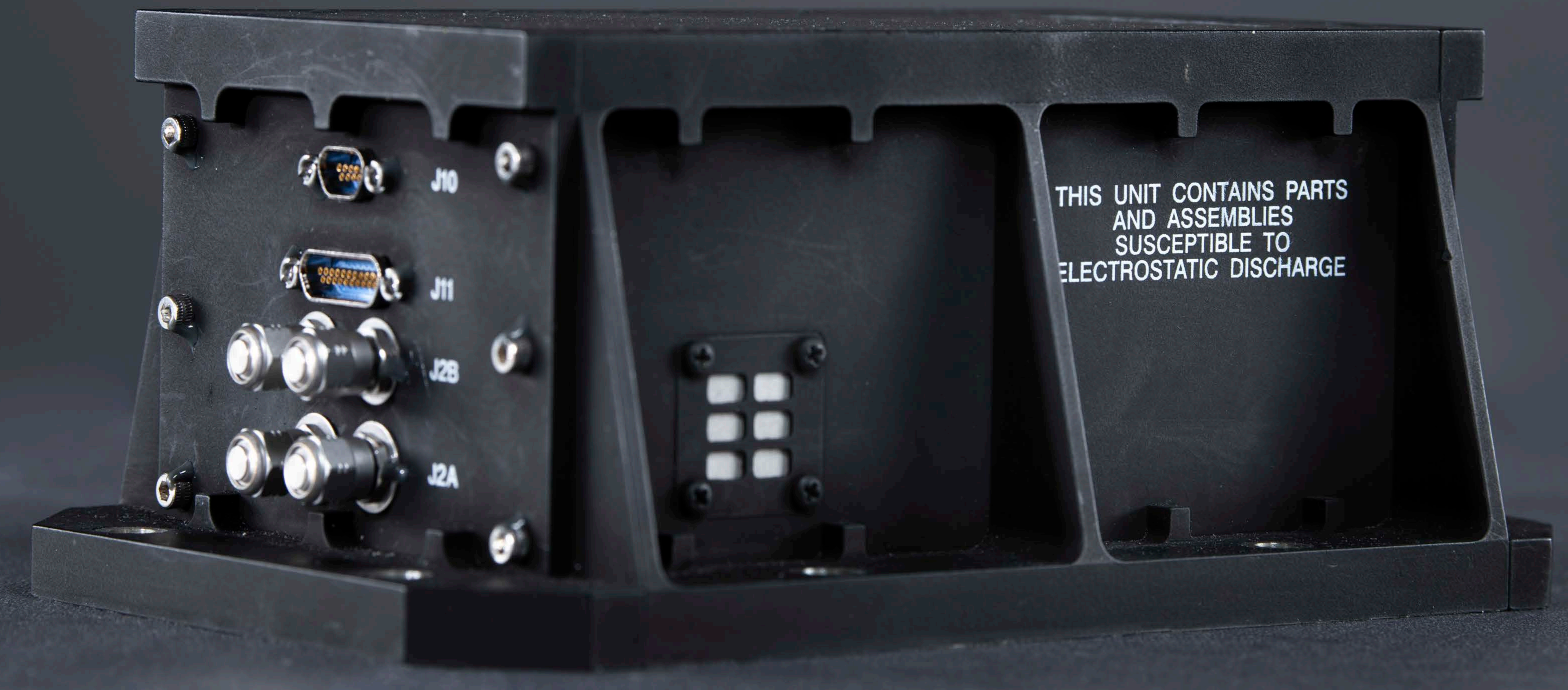




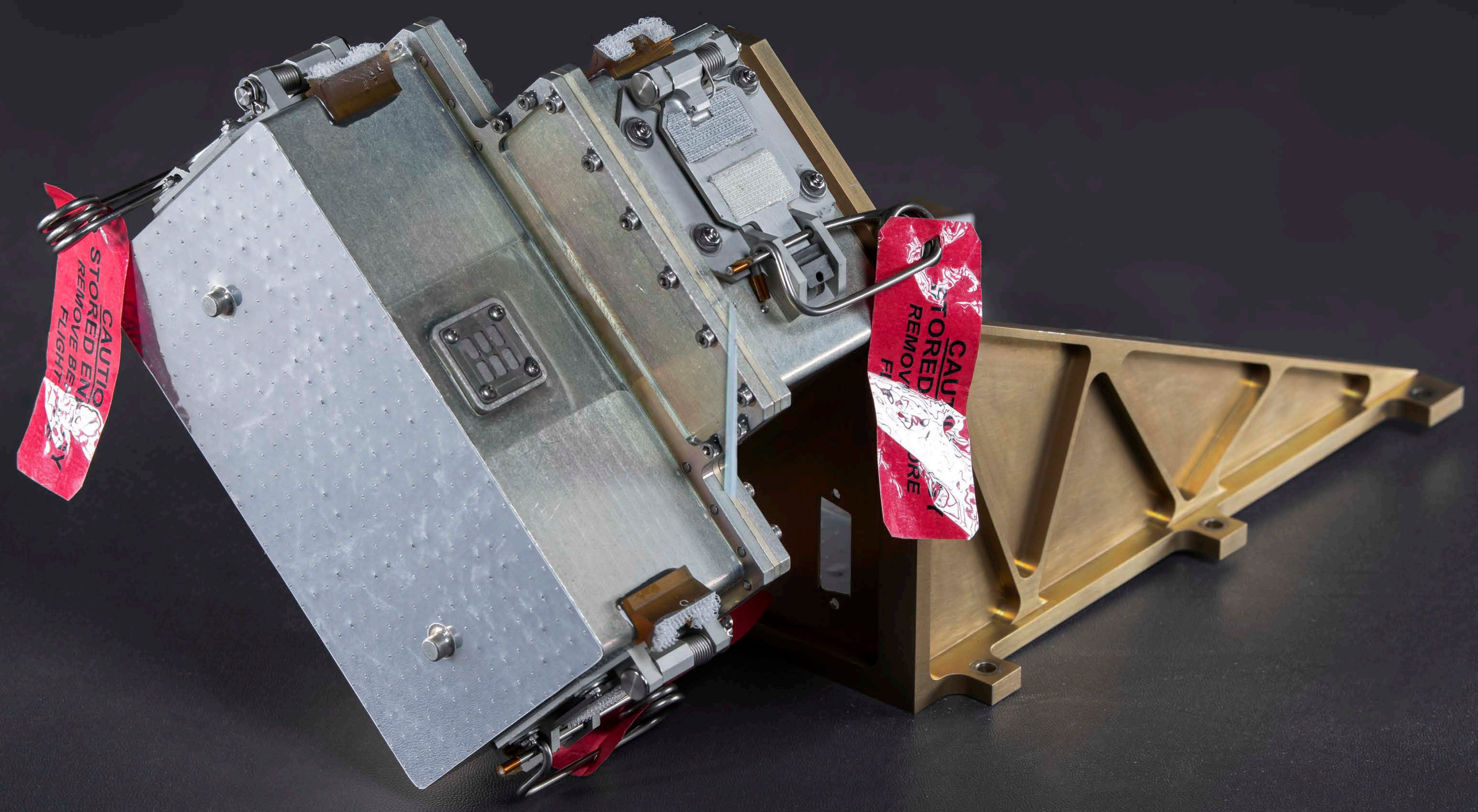




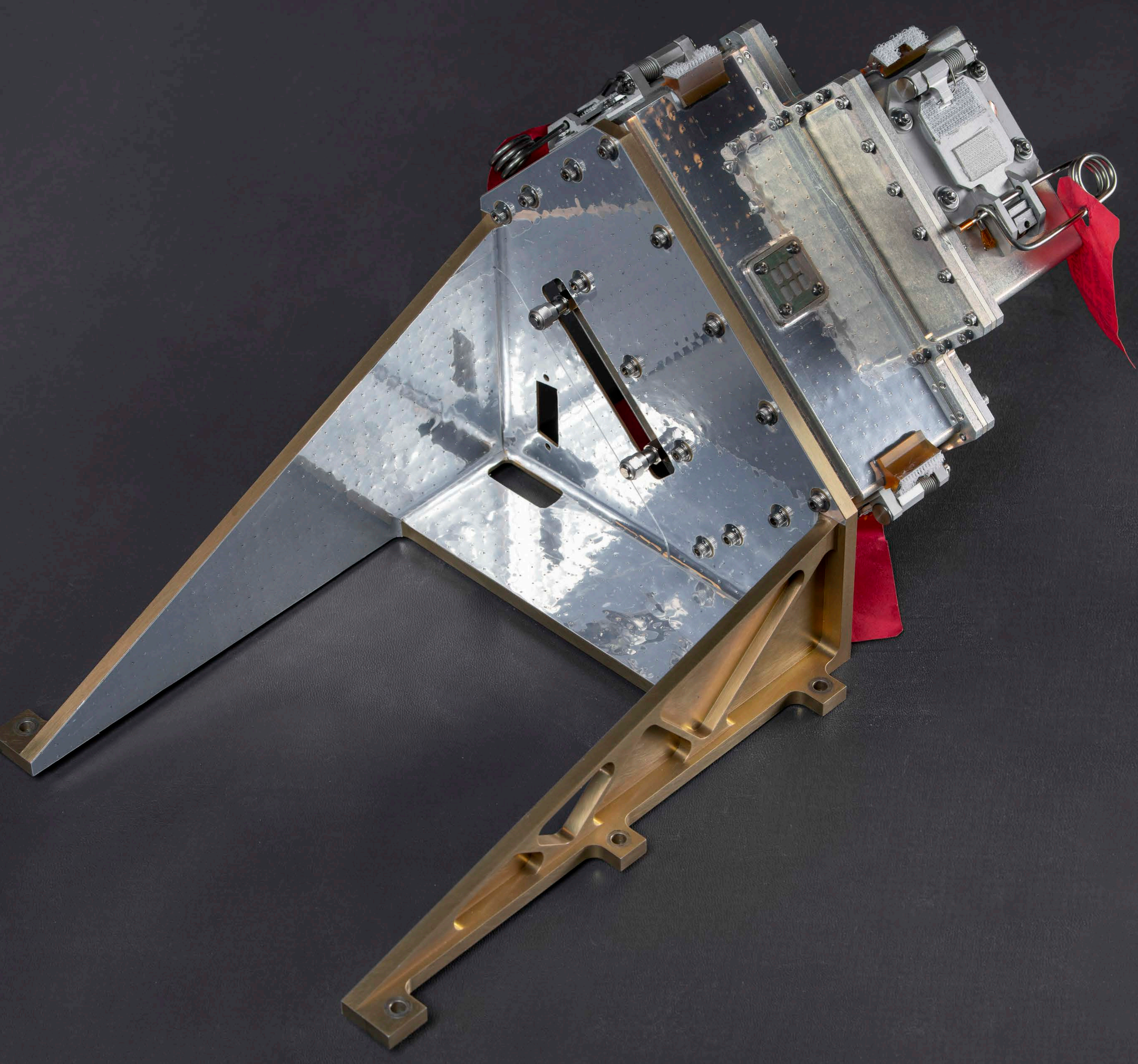


SENSER - RROE 


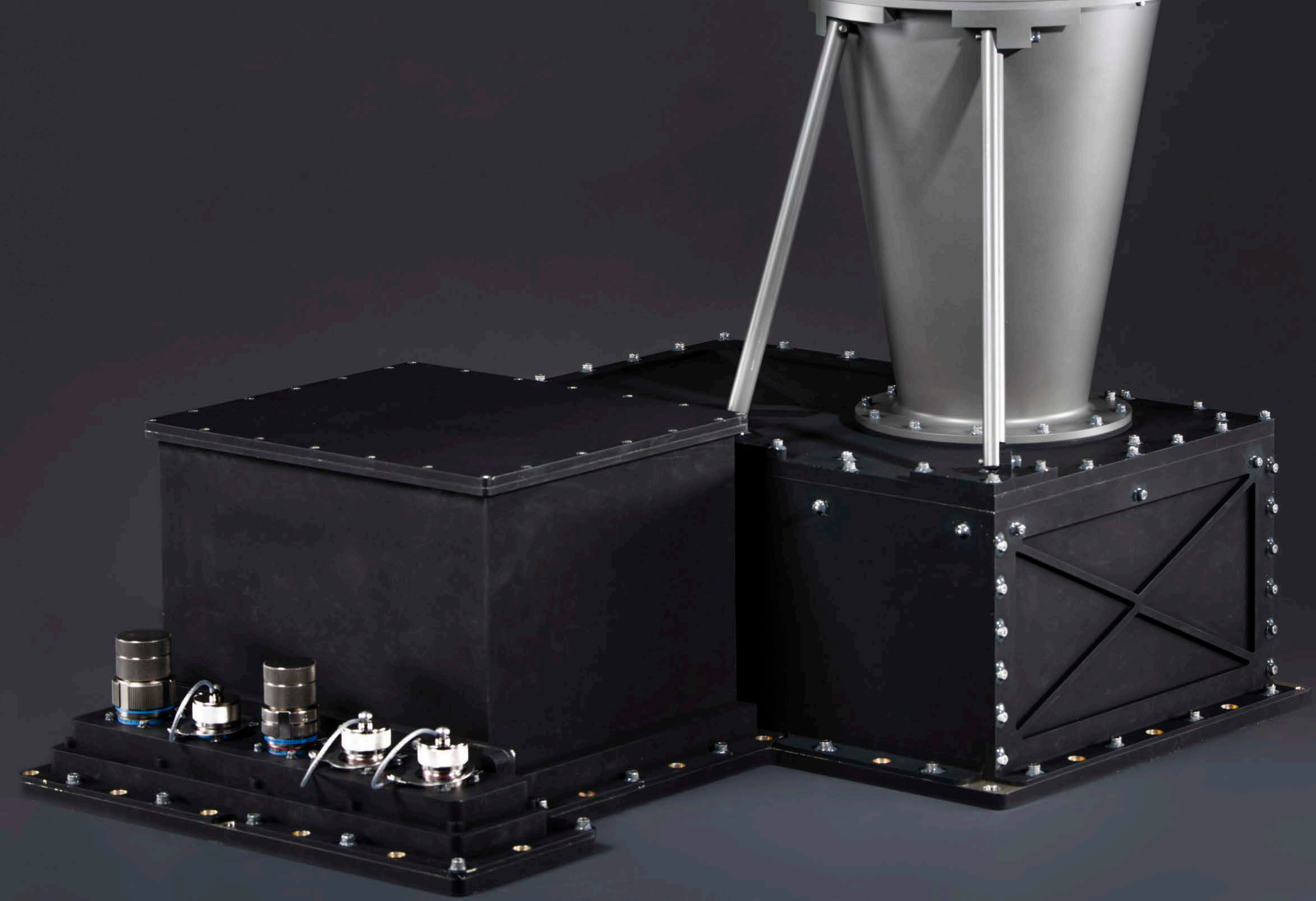



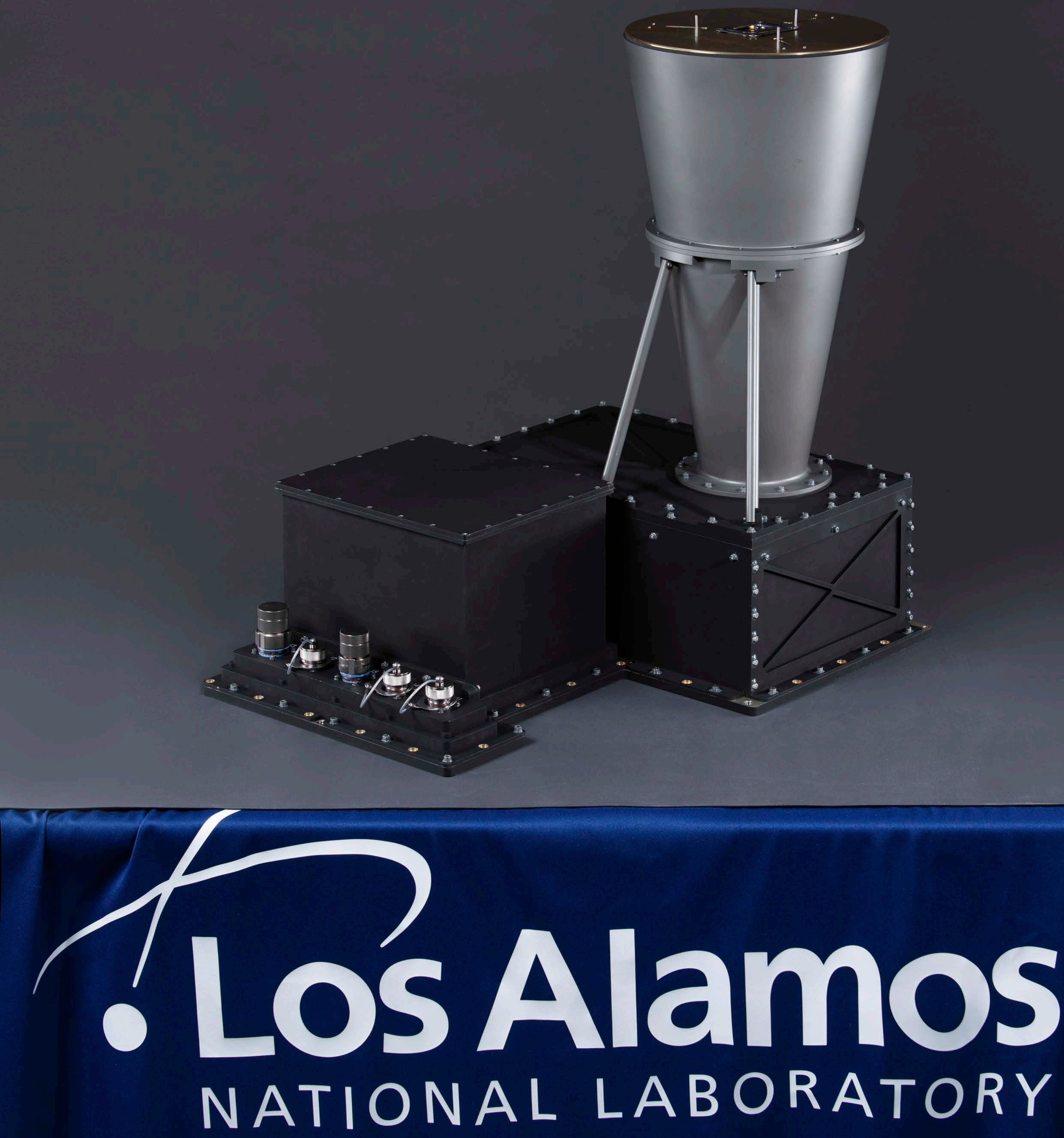

EST. 1943 


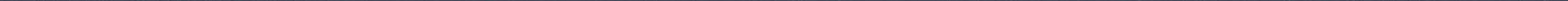




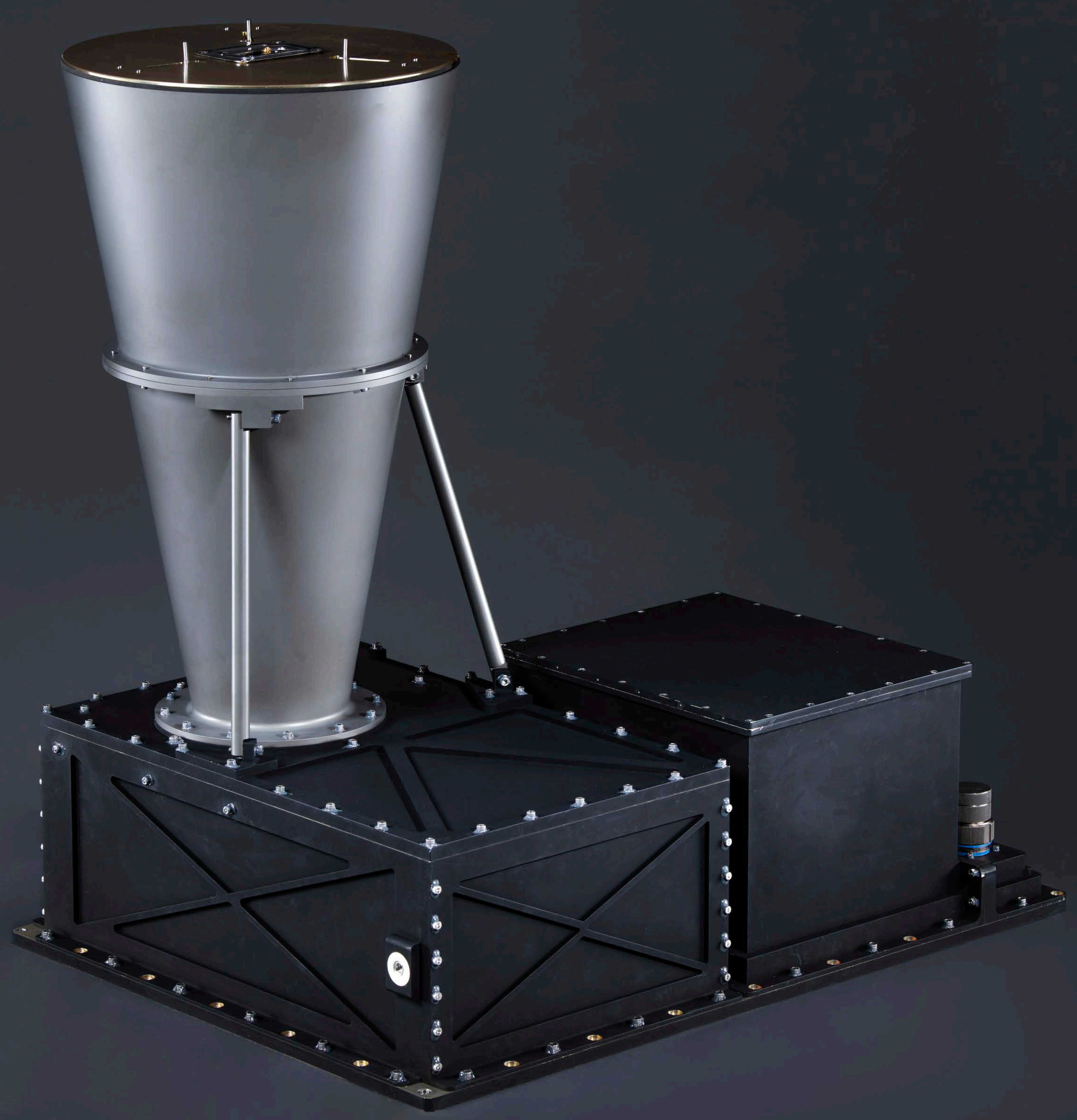




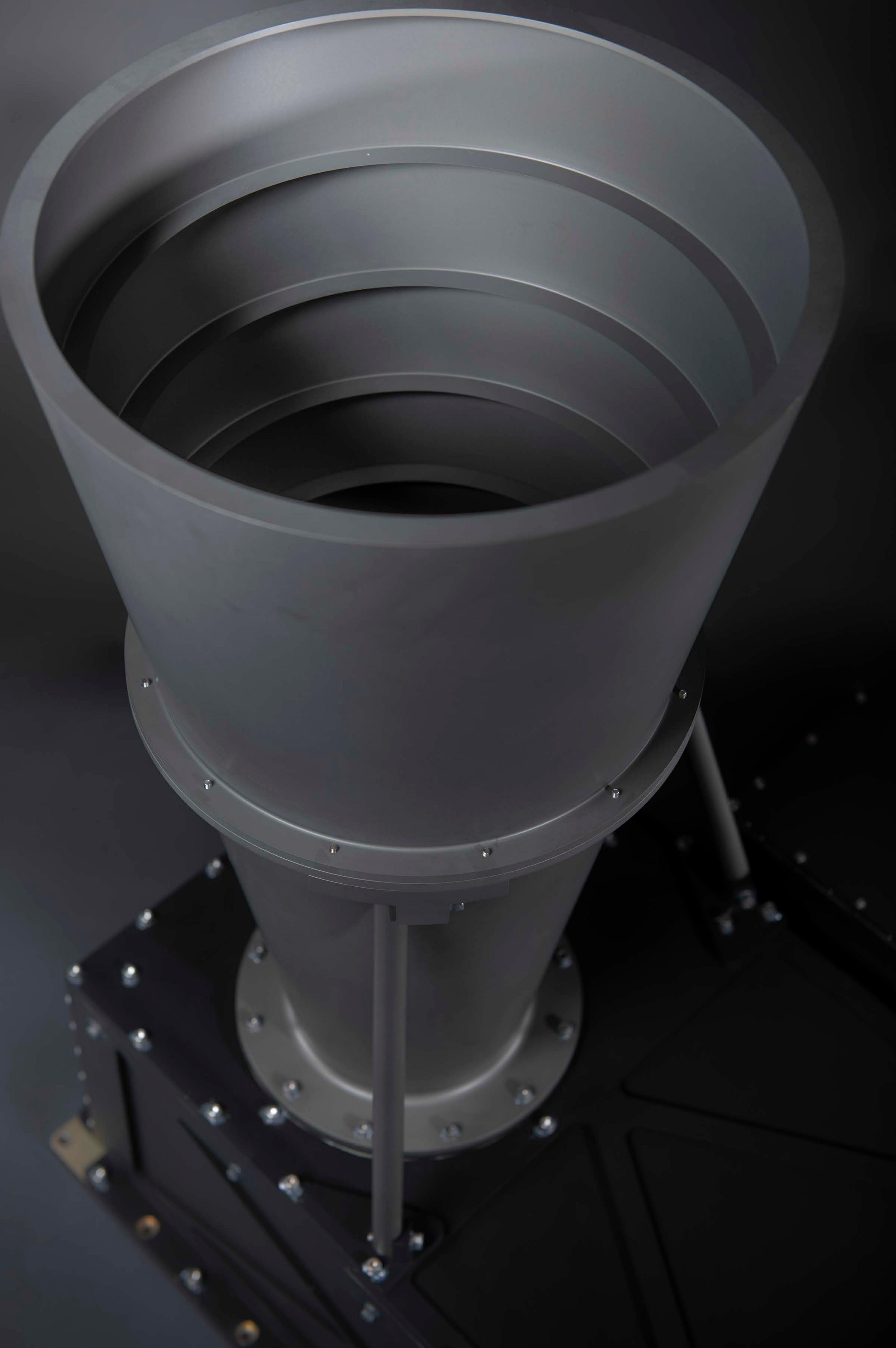




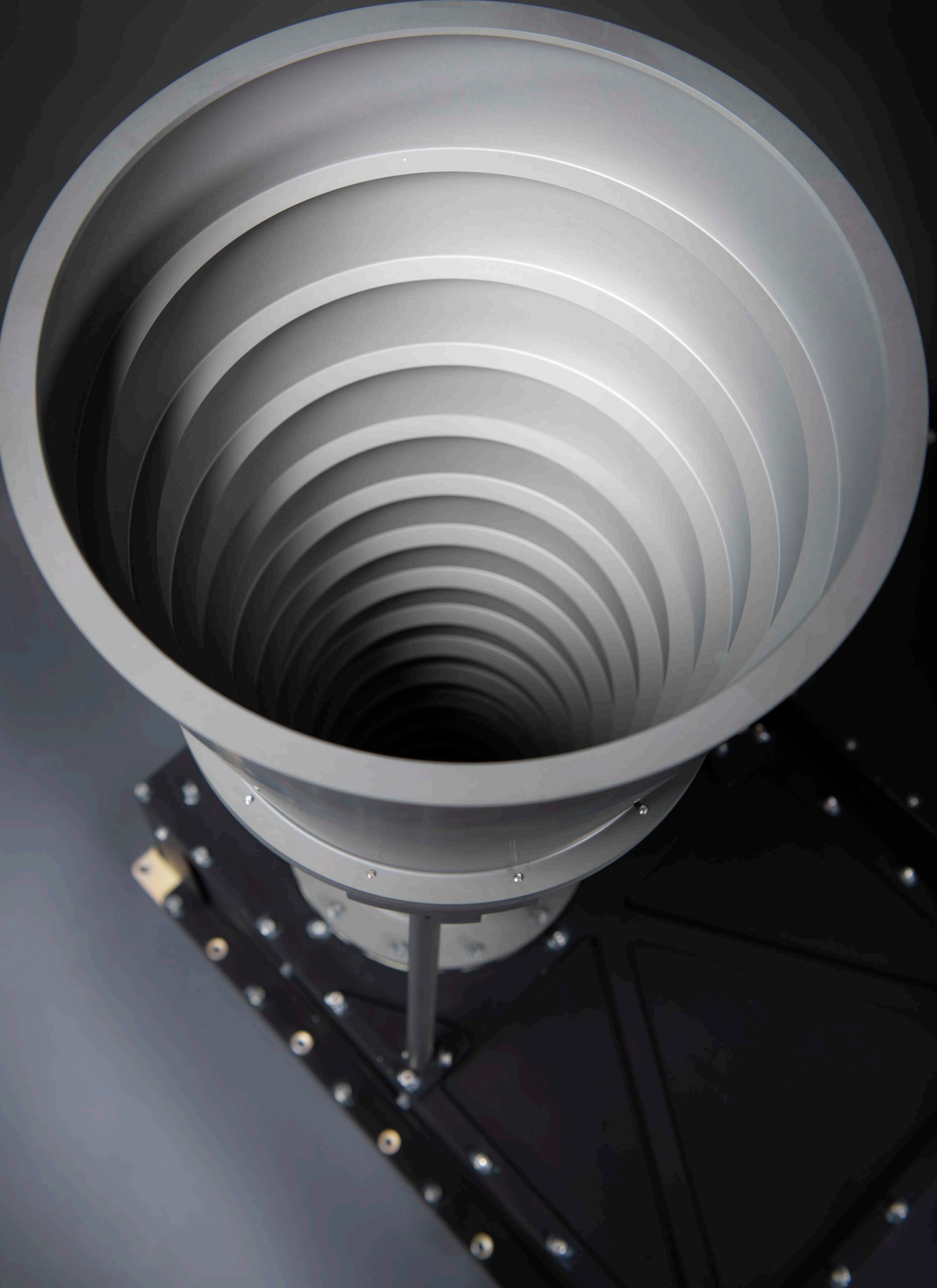




\section{SENSER - HRE Team}






\section{SENSER - RFS Team}


SENSER - RROE Team 


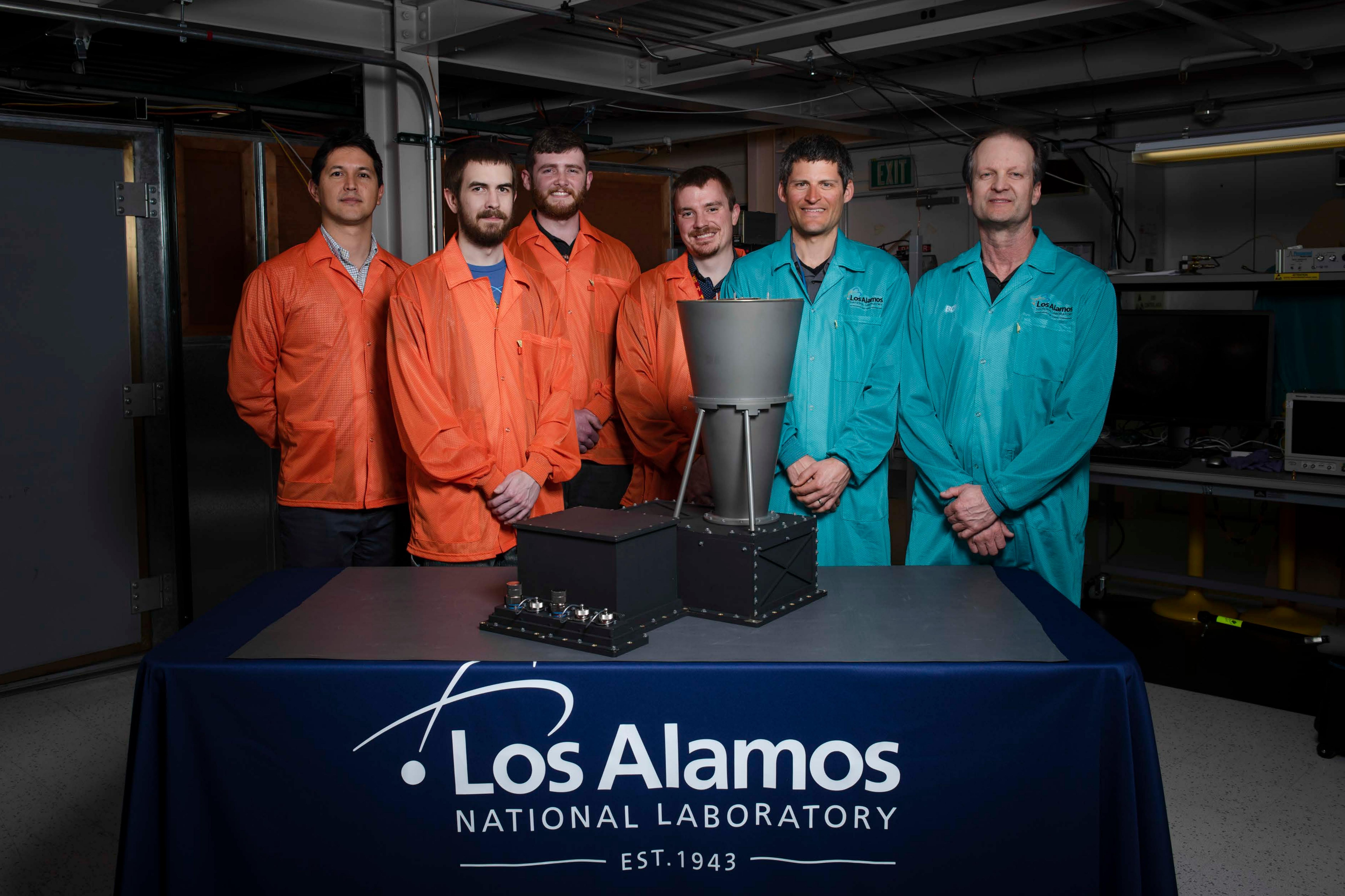




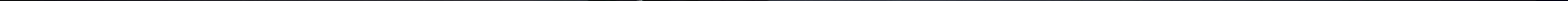




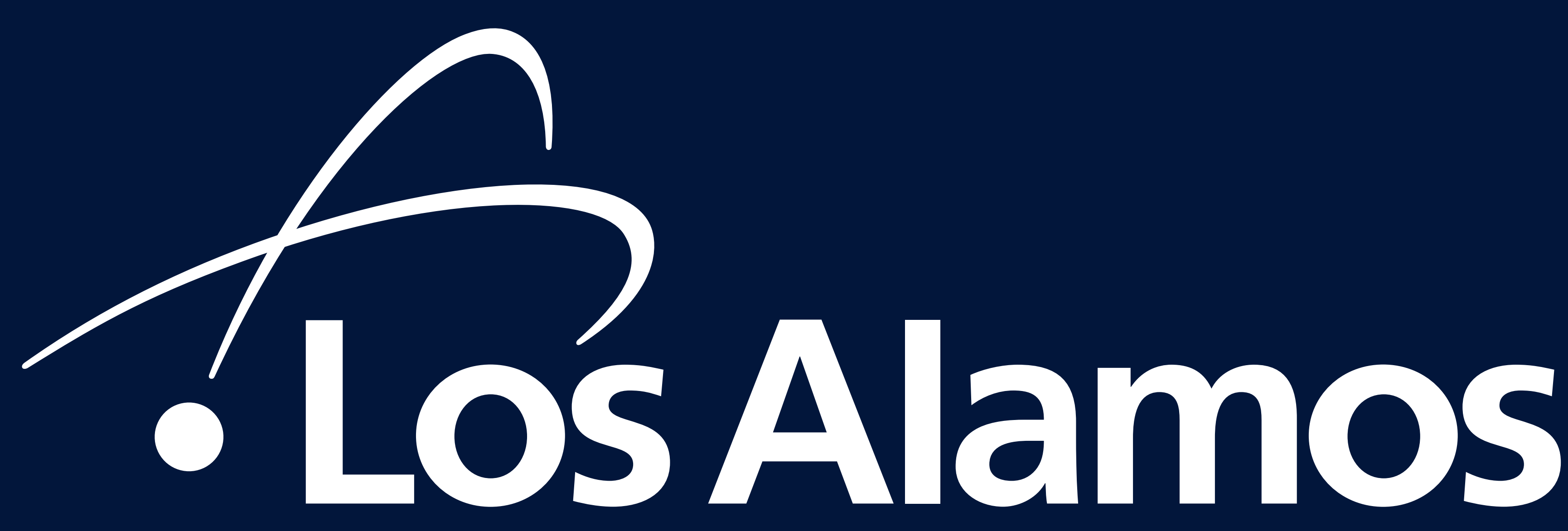
NATIONAL LABORATORY

EST. 1943 